\title{
Le Corbusier: Relações entre as obras arquitetônicas e de design do arquiteto e suas observações da natureza
}

\section{Le Corbusier: Relations between the architect's architectural and design works and his observations of nature}

DOI: $10.46814 / 1 a j d v 3 n 1-005$

Recebimento dos originais: 30/12/2020

Aceitação para publicação: 23/12/2020

\section{Myrna de Arruda Nascimento \\ Doutora}

Instituição: Universidade de São Paulo (FAUUSP) e Centro Universitário SENAC Endereço: Centro Universitário Senac - Av. Eng. Eusébio Stevaux, 823 - Santo Amaro, São Paulo SP, 04696-000; Faculdade de Arquitetura e Urbanismo da Universidade de São Paulo - Rua do Lago,

876- Butantã, São Paulo - SP, 05508-080

E-mail:myrna@usp.br; myrna.anascimento@sp.senac.br; myrnanas@gmail.com

\author{
Alexandre Monteiro da Cruz \\ Bacharel em Arquitetura \\ E-mail: al.monteiro.c@gmail.com
}

\begin{abstract}
RESUMO
Este projeto de Iniciação Científica visa estudar a produção do arquiteto e designer Le Corbusier, cujas composições vinculam seus métodos de experimentação tanto formal quanto técnica ao exame minucioso das proporções humanas e naturais. Os resultados de tais experimentos geraram produtos que constituem material valioso para o estudo e aprendizado das possibilidades de produção de objetos a partir da especulação conceitual e projetiva. Através desta pesquisa buscamos compreender o papel da experimentação e especulação formal, conhecidos através do estudo da produção de Le Corbusier, reconhecendo sua contribuição para a vanguarda do Racionalismo Funcionalista.
\end{abstract}

Palavras-chave: Le Corbusier, design, arquitetura, técnica, produção, Funcionalismo.

\begin{abstract}
This Scientific Initiation Project aims to study the production of the architect and designer Le Corbusier, whose compositions entail his testing methods so formal so tecnician to the scrutiny of human and natural proportions. The results of such experiments led to products that are valuable material for study and learning possibilities of production of objects from the conceptual speculation and projective. Through this research we intend to understand the role of experimentation and formal speculation, known through the study of the production of Le Corbusier, recognizing his contribution to the forefront of Funcionalist Racionality.
\end{abstract}

Keywords: Le Corbusier, design, architecture, technique, production, Funcionalism. 


\section{INTRODUÇÃO}

As produções do arquiteto, designer e urbanista Le Corbusier são de grande importância para a constituição da escola moderna de design e arquitetura, bem como para a compreensão da arte e design pois agregam conceitos de análise anatômica à produção artística e industrial. Suas análises estabelecem vínculo entre a dimensão humana, a produtiva, a edificada e a urbana, levando em conta inovações e especificidades materiais e tipológicas. Sua produção em design impregna-se do conceito de equipamento doméstico.

Nas obras de Corbusier a forma é resultado lógico da problematização bem formulada, equilibrada, ordenada e sem resíduos, sendo solução da relação objeto-edifício-natureza, harmonizando as proporções entre coisa e espaço.

\section{OBJETO DA PESQUISA}

O projeto objetivou estudar as relações existentes entre forma, espaço e objeto, fundamentandose nas produções de Le Corbusier, ressaltando suas observações de proporções e seu caráter racionalista funcionalista. A pesquisa também analisou os processos criativos deste arquiteto e designer, especialmente no tocante a adequação de seus projetos à produção industrial.

\section{METODOLOGIA}

1. Levantamento bibliográfico.

2. Análise de aspectos teóricos e conceituais relativos a arte, técnica, tecnologia e ciência.

3. Fatores histórico-culturais relevantes para o desenvolvimento de seus projetos.

4. Levantamento iconográfico de exemplos que possibilitem o estudo de conceitos e métodos produtivos do designer.

5. Organização dos exemplos em vista da abordagem teórica e dos parâmetros de análise selecionados.

6. Redação de pressupostos teóricos e dos critérios adotados para organização e estudo do material levantado.

7. Edição final da pesquisa.

\section{RESULTADOS E DISCUSSÃO}

A partir da leitura de "The Master Builders", de Peter Blake (1996), identificou-se no desenvolvimento da obra de Le Corbusier diversos fatores que impulsionam sua criação. Em 1910 o arquiteto viaja a Alemanha, estabelecendo contato com Peter Behrens, participando da conferência do grupo Deutscher Werkbund. Relaciona o funcionalismo materialista aos excessos do Expressionismo, 
gerando o Purismo. Empreende uma Viagem ao Oriente. Neste trajeto valoriza a utilização de módulos como expressão do espírito de uma época ao tomar contato com obras clássicas.

Blake (1996) ressalta três eventos na Europa como de grande valor ao desenvolvimento da arquitetura moderna e da produção futura de Corbusier:

a) A publicação dos dois volumes, em 1910 e 1911, pela editora berlinense Wasmuth de "Executive Buildings and Projects by Frank Lloyd Wright" e a exposição dos trabalhos de Wright em Berlim, claros e sofisticados;

b) O projeto e construção em 1911 e 1914, por Gropius e Meyer, da fábrica Fagus e do edifício Werkbund;

c) O desenvolvimento da pintura e escultura moderna, especialmente o Cubismo e o Futurismo, movimentos cujos objetos e temas passaram a ser representados sob vários ângulos e vistas, ao mesmo tempo, de modo que os arquitetos, a partir de Gropius, geraram edifícios observadores de todo redor.

Em termos de estudos formais, Le Corbusier trabalhou volumes simples de modo engenhoso: cilindros, cubos, cones e esferas, salientando a apreciação da forma por ela mesma. Buscou formular uma nova ordem estética na França, sintonizada com as raízes mediterrâneas da cultura nacional. Corbusier exalava um romantismo nascido da grandeza das civilizações do Mediterrâneo, em sua particular e fabulosa tradição expressa nas massas e volumes construídos no Antigo Egito, em Roma, na Grécia e na Renascença. Para ele os silos, galpões e fábricas manifestam a grandiosidade de massas sob a luz oriunda dos períodos clássicos. A nova estética da máquina o levava a raciocinar sobre seus efeitos na produção de arquitetura, com a adesão de dimensões padronizadas. Usou a proporção áurea para definir o projeto da Capela Ronchamp.

Entre 1918 e 1921 se preocupou com as leis gerais governantes tanto da pintura quanto da arquitetura. Seus estudos consideraram as teorias urbanísticas de Garnier, com sua Cidade Industrial, e de F. W. Taylor, para elaborar o conceito da "máquina de morar". Com base nesse conceito elaborou diversos projetos, definindo não apenas aspectos cívicos, mas níveis de sistemas de transporte. No período entre 1926 e 1929 projetou cinco residências (Cook House, Villa Stein, duas Weissenhof e a Ville Savoye), demonstrando com clareza os cinco pontos arquitetônicos modernos. Esses itens são: construção suspensa por pilotis, planta interna livre, fachada livre, janela em comprimento ou fita, e terraço jardim. A adoção de pátios privados e grandes salas leva Corbusier a projetar móveis adequados a tais ambientes, a partir de 1926, em parceria com Pierre Jeanneret, seu irmão e com Charlotte Perriant, como a chaise-longue LC4, quase similar a um divã, a poltrona LC3, adequados à produção seriada. (Fig 1,2 e 3) 
Fig. 1, 2 e 3 Casa La Roche: vista do pátio interno; chaise-longue LC4 presente na sala; rampa interna da residência.

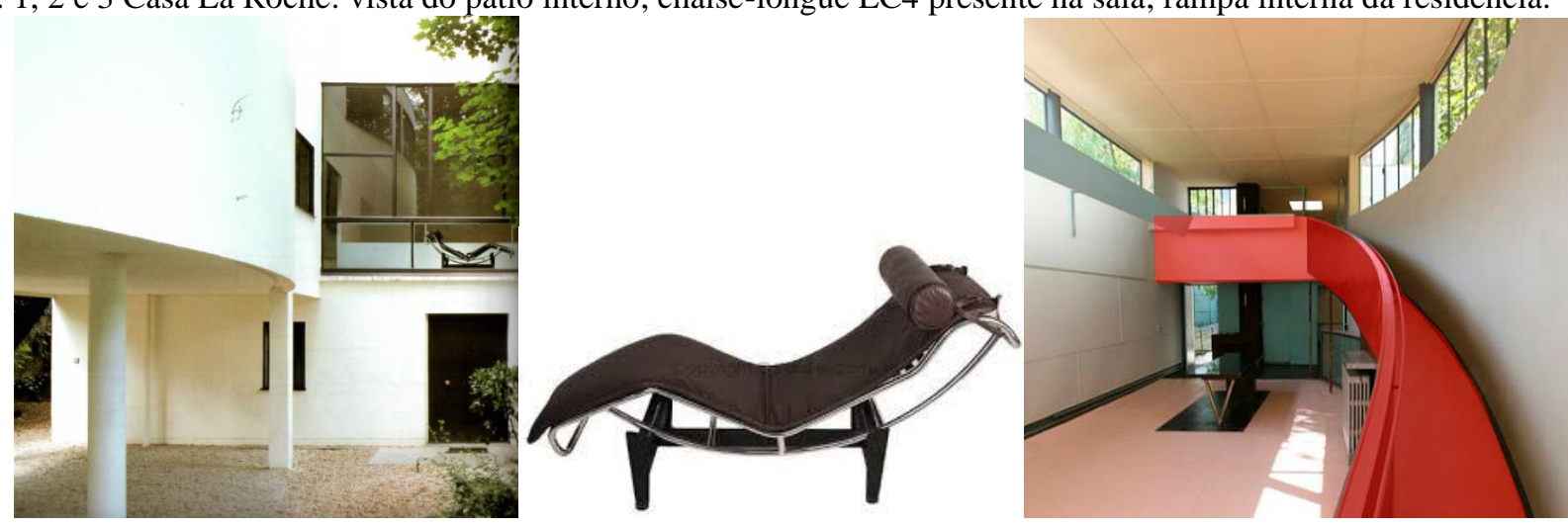

As observações do ambiente natural proveram inspiração que se irradiou por diferentes campos: a indagação formal, a presença da luz no espaço construído, as variadas dualidades como o complexo jogo entre cheios e vazios, unitários e múltiplos, grandiosidade e reprodutibilidade, premissas de conforto, valendo-se de investigações múltiplas que ocasionaram desdobramentos caracterizadores de sua produção. Ampliou algumas das ideias puristas à arquitetura.

No Pavilhão Suíço (1930) elabora o fragmento de uma cidade ideal. No Plano Obus para Argel um programa mais amplo integra a mecanização com imperativos regionais. A visão olímpica das plantas urbanas dos anos 1930, em parte, surge da imagem que o avião lhe permitiu captar. Neste período reagiu à crise mundial, consoante a seus contemporâneos, insistindo no papel da natureza no realinhamento dos indivíduos e da sociedade, como mostrado em seus projetos de condomínios em Argel, escolas e abrigos temporários para refugiados, além de casas de veraneio por outras partes do mundo. Para ele as bases de tal visão pessoal estavam nas ideias utópicas do Iluminismo. $\mathrm{O}$ arquiteto considerava-se um humanista crítico.

Em Cap Martin aliou suas visões sobre o uso do Modulor, a moradia mínima ideal e a integração com o ambiente natural. No convento de La Tourette (1957) releu padrões românicos, reafirmando uma nova terminologia estrutural em concreto. De 1951 a 1965, nos projetos para Ahmadabad e Chandigarh (Fig 4 e 5), demonstraria seus argumentos urbanísticos e tipológicos inspirados por questões regionais e idealistas. Adotou elementos inorgânicos e anímicos nessa época na Capela Ronchamp (1950-54), ressaltando a experiência do local, a implantação e o interior. Na Unidade Habitacional de Marselha (1947-53) estabeleceu diversos vocabulários individuais ao abordar a préfabricação, a hierarquia dos apartamentos individuais em relação ao conjunto total, os espaços privados em relação aos públicos, os pilotis definidores da galeria, a reconciliação entre o problema da demanda habitacional e a dotação de prazeres individuais. 
Fig. 4 e 5 Parlamento de Chandigarh: inserção na paisagem e mesa criada especificamente a este projeto por Corbusier e Pierre Jeanneret.

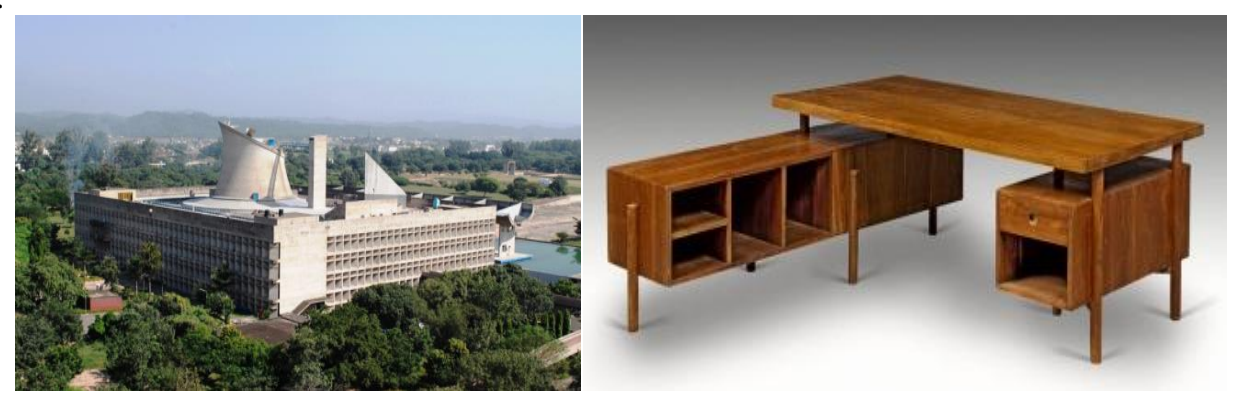

Seu trabalho utiliza a natureza de várias maneiras, relacionando a escala humana ao ambiente construído. Tal processo dá-se por recursos variados. Ocorre a investigação sobre as proporções humanas no estudo de elaboração do Modulor, um sistema de padronização de medidas harmonizando as atividades cotidianas com a escolha de dimensões dos ambientes. Também notamos a utilização do modelo celular como organizador dos espaços internos e circulação dos edifícios, o conceito de tecido na elaboração de planos urbanos e distribuição de volumes no terreno de implantação de seus projetos. Por um procedimento analisado como Ecologia da Imaginação o arquiteto elabora estruturas espaciais ordenadoras da experiência humana. A arquitetura é um elemento produtor de fenômenos sensoriais.

Assim como vários de seus contemporâneos, procurou responder às demandas de um período de severas transformações nos padrões sociais e produtivos, encontrando elementos diferentes dele em algumas abordagens dessa busca. Exemplos são os usos de materiais brutos, mais presentes em Alvar Aalto e a elaboração de claraboias por esse, relacionando os ambientes interiores e exteriores diferentemente de Corbusier. Em palestras e congressos abordou o desenvolvimento urbano e suas relações com obras arquitetônicas individuais, ressaltando a importância da contribuição dos arquitetos e urbanistas no bom andamento das cidades contemporâneas.

\section{CONCLUSÕES}

A elaboração dessa pesquisa propiciou o contato com diversos recursos possíveis de uso como fonte de repertório e linguagem para elaboração de projetos. Estes certamente alimentaram as soluções adotadas nas obras geradas pelo arquiteto. Há no começo da vida profissional de Corbusier sua experiência como relojoeiro. Após esse período ocorrem suas viagens pela Alemanha, Itália e Oriente, onde capta a essência dos modelos clássicos e vernaculares. Depois toma contato com cenários tão diversos como o Norte da África, a América do Sul e a Índia, incorporando elementos regionais e anímicos a seus projetos. É notada a importância do conhecimento de tipologias sem limitar-se a abordá-las de forma padronizada. Esse percurso intelectual de Corbusier enriquece os futuros projetos e análises deste e de todo pesquisador. 


\section{REFERÊNCIAS}

BLAKE, Peter. The master builders. New York: Norton \& Company, 1996.

COLQUHON, Alan. Modern Architecture. New York: Oxford University Press, 2002.

COOK, Theodore Andrea. The curves of life. New York: Pover, 1979.

CORBUSIER, Le. A arte decorativa. Porto Alegre: Martins Fontes, 1996.

"A aventura do mobiliário" in Precisões sobre um estado presente da arquitetura e do urbanismo. São Paulo: Cosac \& Naify, 2004.

Le Corbusier sketchbooks. London: Thames \& Hudson, 1981.

Modulor: ensayo sobre una medida armonica a la escala humana aplicable universalmente a arquitectura y a la mecanica. Buenos Aires: Poseidon, 1961.

CURTIS, William J. R. Arquitetura Moderna desde 1900. Tradução: Alexandre Salvaterra. Porto Alegre: Bookman, 2008.

Le Corbusier: ideas and forms. London: Phaidon Press, 1986.

MENIN, Sarah; SAMUEL, Flora. Nature and Space: Aalto and Le Corbusier. London: Routledge, 2003.

http://es.wikipedia.org/wiki/Villa_La_Roche\#mediaviewer/Archivo:Rampa_Interior.jpg Acessado em 10 de junho de 2014.

http://www.chandigarh-design.com/en/pierrejeanneret-le-corbusier-desks/103-lecorbusierchandigarh-jeanneret-design-.html

Acessado em 10 de junho de 2014. 